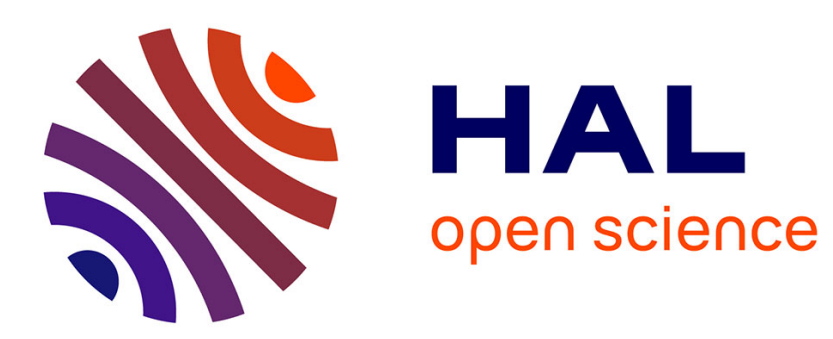

\title{
Correlated detection of neutral and charged fragments in collision induced fragmentation of molecular clusters
}

\author{
H. Abdoul-Carime, F. Berthias, B. Farizon, M. Farizon
}

\section{To cite this version:}

H. Abdoul-Carime, F. Berthias, B. Farizon, M. Farizon. Correlated detection of neutral and charged fragments in collision induced fragmentation of molecular clusters. International Journal of Mass Spectrometry, 2014, 365-366, pp.311-315. 10.1016/j.ijms.2014.01.009 . in2p3-00932145

\section{HAL Id: in2p3-00932145 \\ https://hal.in2p3.fr/in2p3-00932145}

Submitted on 16 Jan 2014

HAL is a multi-disciplinary open access archive for the deposit and dissemination of scientific research documents, whether they are published or not. The documents may come from teaching and research institutions in France or abroad, or from public or private research centers.
L'archive ouverte pluridisciplinaire HAL, est destinée au dépôt et à la diffusion de documents scientifiques de niveau recherche, publiés ou non, émanant des établissements d'enseignement et de recherche français ou étrangers, des laboratoires publics ou privés. 


\title{
Correlated detection of neutral and charged fragments in collision induced fragmentation of molecular clusters
}

\author{
H. Abdoul-Carime, F. Berthias, B. Farizon, M. Farizon \\ Université de Lyon, F-69003, Lyon, France; Université Lyon 1, Villeurbanne; CNRS/IN2P3, \\ UMR5822, Institut de Physique Nucléaire de Lyon; F-69622, Villeurbanne.
}

\begin{abstract}
:
We report on collision induced fragmentation of isolated molecular nanosystems studied with an event by event detection technique including the correlated detection of both neutral and charged fragments. This work focuses on the dissociation induced by collisional excitation without ionisation and electron-capture. Two molecular cluster cations are investigated: the collision of protonated hydrogen clusters at $60 \mathrm{keV} / \mathrm{amu}$ with helium targets and that of protonated water clusters at $8 \mathrm{keV}$ with an argon gas. In addition to the molecular evaporation process the dissociation channel leading to the production of the $\mathrm{H}_{3}^{+}$or $\mathrm{H}_{3} \mathrm{O}^{+}$ molecular cations (loss of all the molecules) is observed with an unexpected abundance. The cross section for the production of these cations is observed to increase with the number of molecules in the cluster. Such an increase cannot be associated with the direct collisional excitation of the cation core of the cluster.
\end{abstract}

Keywords: Irradiation, nanosystems, biomolecules, clusters, collision induced dissociation, excitation and relaxation, multiparametric event by event detection 


\section{Introduction}

The effect of the ionizing radiation in molecular nanosystems is emerging as a major and open area of research, both on a fundamental level and as a source for experimental and technical innovations. From the experimental standpoint, it has great potential for new applications in analytical sciences and for the development of new synthesis techniques. Concurrent theoretical progress can provide new descriptions of the radiative energy transfer in terms of molecular processes, opening new perspectives in several research areas such as the elucidation of the radiation dose at the molecular scale in living systems ${ }^{1}$, the investigation of molecules which inhibit or counter the effects of irradiation but also in the context of astrochemistry and astrobiology the chemical evolution of interstellar molecular clouds ${ }^{2}$.

Pioneering works have demonstrated the possibility of irradiating molecular nanosystems in the gas phase $\mathrm{e}^{3,4,5}$. During the last decade ion-induced excitation up to ionization and fragmentation has been studied for isolated biomolecules. This opens a novel field of experimental investigation giving access to the initial radiation-induced interactions between molecules and providing key information for the description of the radiation effects at the nanoscopic scale. Although so far limited to the detection and the identification of the produced ion fragments in recent studies it has been extended to the analysis of ions and neutral formed in single events ${ }^{6,7}$ or to the detection of neutrals species ${ }^{8}$. Nevertheless directly monitoring all ionized and neutral fragments produced and their correlations within a single fragmentation event - as will be described in the following - is a major step towards the complete description of the physics and chemistry of the reaction. In this paper we present results on the fragmentation of isolated nanosystems in gas phase induced by collision onto atom targets and where neutral and charged fragments are detected in an event by event frame. In the first part of this contribution, we report on fragment production spectra issued 
from the dissociation of protonated hydrogen clusters at $60 \mathrm{keV} / \mathrm{amu}$. The second part will focus on the fragment production spectra issued from the dissociation of protonated water clusters at $8 \mathrm{keV}$.

\section{Collision Induced Dissociation of protonated hydrogen clusters at 60keV/amu}

The hydrogen cluster ions are the simplest ionized molecular complexes that for decades have attracted experimental efforts to clarify their structure and properties ${ }^{9}$. Quantum Monte Carlo simulation ${ }^{10}$ and quantum chemical calculations ${ }^{11}$ have investigated the effect of the protonation of pure hydrogen clusters $\left(\mathrm{H}_{2}\right)_{\mathrm{m}}$ at low temperature. It has been shown that the added proton is trapped as a localized $\mathrm{H}_{3}{ }^{+}$core surrounded by stable shells of solvating $\mathrm{H}_{2}$ molecules. In the present experiment the measurement of all the ionized and neutral fragments produced and their correlations within a single fragmentation event allows the detailed investigation of the processes involved in the subsequent fragmentation from excitation up to ionization.

\section{I-A Experimental set-up}

Mass selected hydrogen cluster ions with an energy of $60 \mathrm{keV} / \mathrm{amu}$ were prepared in a high-energy cluster ion beam facility ${ }^{12}$ consisting of a cryogenic cluster jet expansion source combined with a high performance electron ionizer and a two-step ion accelerator. After the momentum analysis by a magnetic sector field, the mass selected high energy projectile consisting in the present study of $\mathrm{H}_{3}{ }^{+}\left(\mathrm{H}_{2}\right)_{1 \leq \mathrm{m} \leq 16}$ cluster ions is crossed perpendicularly by a helium target beam effusing from a cylindrical capillary tube ${ }^{13}$. Prior to this the ion beam is collimated by two apertures ensuring an angular dispersion of about $\pm 0.8 \mathrm{mrad}$. One meter after this collision region the high-energy hydrogen collision products (neutral and ionised) 
are passing a magnetic sector field analyser. The undissociated primary $\mathrm{H}_{3}{ }^{+}\left(\mathrm{H}_{2}\right)_{1 \leq \mathrm{m} \leq 16}$ cluster projectile ion or the neutral and charged fragments resulting from reactive collisions are then detected approximately $0.3 \mu$ s after the collision event with a multi-detector device consisting of an array of passivated implanted planar silicon surface barrier detectors located at different positions at the exit of the magnetic analyser. For $60 \mathrm{keV} / \mathrm{amu}$ ions and neutral fragments, detection efficiency is $100 \%{ }^{14}$.

This instrument allows simultaneous recording for each collision event of the number of each mass-identified fragment ion resulting from the interaction ${ }^{12,15,16}$. In addition, for each fragmentation event we can also monitor in coincidence with the detected ions the sum of the masses of all the neutral fragments. Moreover, by probing the angular distribution of these neutrals in front of the detector by using a movable aperture $(0.5 \mathrm{~mm}$ of diameter $)$ it has been demonstrated that the neutral products only consist of hydrogen atoms and hydrogen molecules ${ }^{17,18}$ with no larger neutral clusters present.

Thus thanks to the event-by-event analysis method we are able to identify all correlated fragments produced in a single collision event between the $\mathrm{H}_{3}{ }^{+}\left(\mathrm{H}_{2}\right)_{1 \leq \mathrm{m} \leq 16}$ cluster ion and the He target atom. The fragmentation schemes are in the following general form

$$
\begin{aligned}
& \mathrm{H}_{3}^{+}\left(\mathrm{H}_{2}\right)_{1 \leq \mathrm{m} \leq 16}+\mathrm{He} \rightarrow \mathrm{aH}_{3}^{+}\left(\mathrm{H}_{2}\right)_{\mathrm{p}}+\mathrm{bH}_{3}{ }^{+}+\mathrm{cH}_{2}{ }^{+}+\mathrm{dH}^{+}+\mathrm{e}\left(\mathrm{H}_{2}\right)+\mathrm{fH} \\
& \text { with a-f }=0,1, \ldots \text { and } \mathrm{p}<\mathrm{m} .
\end{aligned}
$$

The validity of single collision conditions has been ascertained by measurements at different He target pressures which allows also to derive absolute cross sections for the occurrence of specific reaction channels (partial cross sections) ${ }^{19}$. This complete analysis allows us to go beyond the straightforward determination of the total charged fragment size distributions as 
reported previously ${ }^{20}$ but also it provides partial fragment size distributions for selected decay reactions or classes of decay reactions.

\section{I-B Results and discussion}

In Figure 1(a) the variety in the fragmentation channels is shown via the histogram of fragmentation events sorted with respect to the value of the sum of the mass (amu) of all the neutral fragments resulting from $\mathrm{H}_{3}{ }^{+}\left(\mathrm{H}_{2}\right)_{11}$ cluster fragmentation. The sum of the mass ( $\left.\mathrm{S}_{\text {neutral }}\right)$ of all the neutral fragments resulting from a fragmented cluster ion $\mathrm{H}_{3}{ }^{+}\left(\mathrm{H}_{2}\right)_{11}$ is directly resulting from the detection technique and we observe 25 separate peaks as described in references [13] and [20]. All the neutral fragments coming from one incident cluster are detected simultaneously. Thus, in the histogram, each event corresponds to the fragmentation of one incident cluster. The number $S_{\text {neutral }}$ associated with each event $\left(S_{\text {neutral }}=1,2,3,4, \ldots, 25\right)$ corresponds to the value of the sum of the mass numbers of all the neutral fragments resulting from the fragmentation of a given cluster. In the following a $S_{\text {neutral }}$ event is defined as a cluster fragmentation event for which the sum of the mass numbers of all the neutral fragments is equal to $S_{\text {neutral }}$.

The histogram built with $10^{4}$ fragmentation events $\left(10^{4}\right.$ dissociated cluster among more than $210^{5}$ incident clusters) sorted with respect to their $S_{\text {neutral }}$ value is presented in Figure 1(a). The histogram can be roughly divided into three $S_{\text {neutral }}$ value ranges corresponding mainly to evaporation process ( $2 \mathrm{amu} \leq \mathrm{S}_{\text {neutral }} \leq 10 \mathrm{amu}$, even), electron capture $\left(S_{\text {neutral }}=25 \mathrm{amu}\right)$ and ionisation $\left(11 \mathrm{amu} \leq \mathrm{S}_{\text {neutral }} \leq 24 \mathrm{amu}\right)$. The ionisation process which corresponds to both odd and even values of $S_{\text {neutral }}$ appears to be involved in about $83 \%$ of the dissociation events observed $^{21}$. These results show importance of ionisation of the incident cluster at $60 \mathrm{keV} / \mathrm{amu}$ incident energy. 
In Figure 1(a), all the fragmentation events are included in the histogram. In contrast the histogram in Figure 1(b) is built by selecting events with a single charged fragment. That corresponds to select only the excitation processes of the precursor, i.e. to exclude collisions leading to electronic capture or ionisation. This histogram demonstrates that only events with even value of $S_{\text {neutral }}$ are resulting from cluster excitation, with the exception for $S_{\text {neutral }}=$ 23amu which is associated with the dissociation of the $\mathrm{H}_{3}{ }^{+}$ion core after excitation:

$$
\mathrm{H}_{3}^{+}\left(\mathrm{H}_{2}\right)_{11}+\mathrm{He} \rightarrow \mathrm{H}_{2}^{+}+\mathrm{H}+11 \mathrm{H}_{2}
$$

Indeed, protonated hydrogen cluster structures are usually represented as an ion core $\mathrm{H}_{3}{ }^{+}$ surrounded by $\mathrm{H}_{2}$ neutral subunits ${ }^{11}$. The events with $\mathrm{S}_{\text {neutral }}=24 \mathrm{amu}$ are also associated with the core dissociation:

$$
\mathrm{H}_{3}^{+}\left(\mathrm{H}_{2}\right)_{11}+\mathrm{He} \rightarrow \mathrm{H}^{+}+12 \mathrm{H}_{2}
$$

In Figure 1(b), the selected events with even $S_{\text {neutral }}$ values ranging from 2 to 22 are associated with the loss of $\mathrm{H}_{2}$ molecules. The corresponding production yield decreases with increasing number of molecules lost. These fragmentation channels are associated with the unimolecular evaporation process ${ }^{22}$. Nevertheless, a relatively high production yield is observed for the events with the value $S_{\text {neutral }}=22 \mathrm{amu}$. This dissociation channel corresponds to the loss of all the molecules:

$$
\mathrm{H}_{3}^{+}\left(\mathrm{H}_{2}\right)_{11}+\mathrm{He} \rightarrow \mathrm{H}_{3}^{+}+11\left(\mathrm{H}_{2}\right)
$$

The abundance of this dissociation channel $\left(S_{\text {neutral }}=22\right)$ is similar to the one leading to the evaporation process of only one hydrogen molecule $\left(S_{\text {neutral }}=2\right)$.

From these production yields and additional measurements, several partial crosssections have been deduced. Several partial cross sections are reported in Figure 2 versus m, the number of molecules, from $\mathrm{m}=1$ to 16 at a given velocity $\left(60 \mathrm{keV} / \mathrm{amu}, \mathrm{v} \approx 3.3810^{6} \mathrm{~m} . \mathrm{s}^{-1}\right)$. For the evaporation of one molecule (eq. 5), the cross-section increases with increasing number of molecules in the cluster. 


$$
\mathrm{H}_{3}^{+}\left(\mathrm{H}_{2}\right)_{\mathrm{m}}+\mathrm{He} \rightarrow \mathrm{H}_{3}^{+}\left(\mathrm{H}_{2}\right)_{\mathrm{m}-1}+\mathrm{H}_{2} \quad \text { with } 1 \leq \mathrm{m} \leq 16
$$

An increase of the cross section for the loss of a single molecule is expected since the binding energy of the molecule lost decreases with increasing number of molecules in the cluster. Size effects are observed and are related to relative stability of the clusters for different number of molecules. More surprising is the observation of a similar behaviour for the cluster dissociation in all its constituents.

$$
\mathrm{H}_{3}^{+}\left(\mathrm{H}_{2}\right)_{\mathrm{m}}+\mathrm{He} \rightarrow \mathrm{H}_{3}^{+}+\mathrm{m}\left(\mathrm{H}_{2}\right) \quad \text { with } 1 \leq \mathrm{m} \leq 16 \text { (6) }
$$

The cross-section associated with this process increases with increasing number of molecule in the cluster. The cross-section increases from $m=1$ up to $m=5$ then it is nearly constant up to $m=13$ and then it increases up to 16 . Such dissociation process might be related to a collisional excitation of the $\mathrm{H}_{3}{ }^{+}$core inducing the complete dissociation of the cluster. But cross-sections for dissociation processes associated with the core excitation show a different behaviour with the increase of the number of molecules in the cluster. Indeed, in Figure 2 are also reported the cross-sections for the two following dissociation channels:

$$
\begin{aligned}
& \mathrm{H}_{3}{ }^{+}\left(\mathrm{H}_{2}\right)_{\mathrm{m}}+\mathrm{He} \rightarrow \mathrm{H}^{+}+\mathrm{H}_{2}+\mathrm{m}\left(\mathrm{H}_{2}\right) \text { with } 0 \leq \mathrm{m} \leq 16 \\
& \mathrm{H}_{3}{ }^{+}\left(\mathrm{H}_{2}\right)_{\mathrm{m}}+\mathrm{He} \rightarrow \mathrm{H}_{2}^{+}+\mathrm{H}+\mathrm{m}\left(\mathrm{H}_{2}\right) \text { with } 0 \leq \mathrm{m} \leq 16
\end{aligned}
$$

The cross-section for these two processes are observed to be constant in the cluster range studied. Such results are in agreement with the results on electron-capture cross section of protonated hydrogen clusters. Indeed, the electron capture cross section is independent of the cluster size and nearly equal to the capture cross section of the $\mathrm{H}_{3}{ }^{+}$core ${ }^{23}$. Therefore, the excitation of the $\mathrm{H}_{3}{ }^{+}$core cannot explain the increasing with the cluster size of the cross sections associated with the cluster dissociation in all its constituents. 


\section{Collision Induced Dissociation of protonated water clusters on argon gas target at 8}

keV

Progress in the molecular-scale understanding of cellular processes and the development of molecular analysis techniques have triggered key questions related to the effects of ionizing radiation upon living material ${ }^{24,25,26,27,28}$. For instance, technical advances have opened possibilities for the study of biological molecules seeded in clusters of water molecules, and hence an entirely new perspective ${ }^{29}$. This intermediate step between the isolated molecule and the condensed phase has great potential as a target medium for research into the effects of ionizing radiation. Indeed the possibility to form a cluster with a welldefined composition, for instance a small "biomolecule" solvated by a given number of water molecules, offers a unique opportunity to quantify the impact of environment on the irradiation process. Moreover, this well-controlled (and possibly small) size provides exceptional opportunities to obtain direct and complete microscopic descriptions of the irradiation process and, to some extent, the subsequent relaxation pathways. Among the experimental set-ups designed for the investigation of irradiation of nanosystems in the gas phase, the DIAM ${ }^{30}$ device (Dispositif d'Irradiation d'Agrégats Moléculaires) produces high intensity beams of mass-and-energy selected molecular and cluster ions. Moreover a mass spectrometric MS-MS method based on Time Of Flight measurements performed on an event-by-event detection technique has been also developed to explore CID fragmentation processes by directly identifying not only all ions and neutral fragments produced but also their arrival time correlations within each single fragmentation event from a dissociating molecular ion ${ }^{7}$.

\section{II-A Experimental set-up}

Here we focused on the exploration of the fragmentation processes involved in the collision induced dissociation of $8 \mathrm{keV}-\mathrm{H}^{+}\left(\mathrm{H}_{2} \mathrm{O}\right)_{2 \leq \mathrm{m} \leq 7}$ by an argon atom. Briefly, protonated 
water clusters are produced by electron impact in a supersonic nozzle expansion of water vapour. They are accelerated to energy of $8 \mathrm{keV}$ and mass selected by a double focusing sector field mass spectrometer ${ }^{30}$. The energy and mass-selected $\mathrm{H}^{+}\left(\mathrm{H}_{2} \mathrm{O}\right)_{5}$ beam is crossed with an effusive argon gas jet which density is controlled in order to insure single collision conditions in the CID region. The time of flight apparatus involving the COINTOF technique ${ }^{7}$ is mounted right after the CID region along the direction of the incident beam. Any single dissociative collision of a $\mathrm{H}^{+}\left(\mathrm{H}_{2} \mathrm{O}\right)_{5}$ parent ion with an Ar atom produces a daughter ion and one or more neutral fragments. The charged species are then accelerated at $1.8 \mathrm{kV}$ before reaching a field free zone, while the neutral fragments almost keep the initial velocity of the parent ion. All the fragments are then detected by the same Micro Channel Plate detector (MCP, Hamamatsu) with the charged fragment arriving significantly earlier than the neutral species. The MCP signal is sampled by a fast analog to digital converter ( 8 Gsample/s ADC, Acqiris ${ }^{\circledR}$, Agilent) and recorded without dead time during a given arrival time window. The intensity of the initial parent ion beam is controlled in order to ensure that only the fragments of one single parent ion can reach the detector during the detection time window. Therefore, the correlation between the arrival times of the charged and neutral fragments from the dissociation of one single parent ion can be recorded. For each dissociated parent ion, the difference $\Delta \mathrm{T}$ between the arrival time of the charged and neutral fragment is characteristic of the mass over charge ratio(s) of the charged species produced. The charged fragments mass spectrum is deduced from successive measurement of the arrival time difference $\Delta \mathrm{T}$ for a large number of cluster ion dissociation events. The event by event analysis is performed by using ROOT® software.

\section{II-B Results and discussion}

In Figure 3 are reported the difference of arrival time between the accelerated fragment ion and water molecules $(\Delta \mathrm{T})$ issued from the dissociation of $\mathrm{H}^{+}\left(\mathrm{H}_{2} \mathrm{O}\right)_{5}$ ions which 
gives a typical example of the measurements. Thus, the difference of arrival time characterizes the dissociation channel and allows the identification of each peak to a given dissociation channel. Thus the COINTOF method allows to select the dissociation processes versus the arrival times of the fragments in an event by event frame. In the present experiment, we select the dissociation induced by excitation processes excluding the electron capture process ${ }^{31}$. After the interaction with the argon gas target $\mathrm{H}^{+}\left(\mathrm{H}_{2} \mathrm{O}\right)_{5}$ parent ions dissociate in five various dissociation channels, each one corresponding to the loss of a given number of water molecules. At the incident energy of $8 \mathrm{keV}$, dissociation following electronic excitation is the dominant process induced by the collision ${ }^{32}$.

The insert in figure 3 shows an example of the detection signal for a single dissociation event recorded by the fast ADC electronics. It corresponds to the following channel:

$$
\mathrm{H}^{+}\left(\mathrm{H}_{2} \mathrm{O}\right)_{5}+\mathrm{Ar} \rightarrow \mathrm{H}^{+}\left(\mathrm{H}_{2} \mathrm{O}\right)_{3}+2\left(\mathrm{H}_{2} \mathrm{O}\right)
$$

The detection signal exhibits three peaks: the first one corresponding to the fragment ion is followed by two peaks at higher arrival times associated with the two neutral water molecules. A large number of events are recorded. The histogram built by sorting the dissociation events versus the arrival time difference between the charged fragments and the neutral ones gives the charged fragment mass spectrum. In Figure 3, the various dissociation channels can be identified by their specific product ion $\mathrm{H}^{+}\left(\mathrm{H}_{2} \mathrm{O}\right)_{4}, \mathrm{H}^{+}\left(\mathrm{H}_{2} \mathrm{O}\right)_{3}, \mathrm{H}^{+}\left(\mathrm{H}_{2} \mathrm{O}\right)_{2}$, $\mathrm{H}^{+}\left(\mathrm{H}_{2} \mathrm{O}\right)_{1}$ and $\mathrm{H}^{+}$.

Three main dissociation channels observed in the spectrum plotted in Figure 3 can be mainly attributed to the following molecular evaporation processes:

$$
\mathrm{H}^{+}\left(\mathrm{H}_{2} \mathrm{O}\right)_{5}+\mathrm{Ar} \rightarrow \mathrm{H}^{+}\left(\mathrm{H}_{2} \mathrm{O}\right)_{4}+\mathrm{H}_{2} \mathrm{O}
$$




$$
\begin{aligned}
& \mathrm{H}^{+}\left(\mathrm{H}_{2} \mathrm{O}\right)_{5}+\mathrm{Ar} \rightarrow \mathrm{H}^{+}\left(\mathrm{H}_{2} \mathrm{O}\right)_{3}+2 \mathrm{H}_{2} \mathrm{O} \\
& \mathrm{H}^{+}\left(\mathrm{H}_{2} \mathrm{O}\right)_{5}+\mathrm{Ar} \rightarrow \mathrm{H}^{+}\left(\mathrm{H}_{2} \mathrm{O}\right)_{2}+3 \mathrm{H}_{2} \mathrm{O}
\end{aligned}
$$

As discussed previously in the case of protonated hydrogen clusters the molecular evaporation process should lead to a decrease of the relative production yield with increasing the number of molecules lost.

A weak production of $\mathrm{H}^{+}$ions representing at most $0.5 \%$ of the total dissociation of the precursor ions is also observed in Figure 3 suggesting that sufficient energy has been deposited $^{32}$. However the most probable dissociation channel clearly leads to a proton binding to at least a water molecule. From the COINTOF data, the branching ratio for each fragmentation channel can be measured : $0.4,0.229,0.158,0.211$, and 0.0024 , for the production of $\mathrm{H}^{+}\left(\mathrm{H}_{2} \mathrm{O}\right)_{4}, \mathrm{H}^{+}\left(\mathrm{H}_{2} \mathrm{O}\right)_{3}, \mathrm{H}^{+}\left(\mathrm{H}_{2} \mathrm{O}\right)_{2}, \mathrm{H}^{+}\left(\mathrm{H}_{2} \mathrm{O}\right)$ and $\mathrm{H}^{+}$, respectively ${ }^{33}$. The branching ratio values decreases with the increase of the number of evaporated water units, excepted for the production of the $\mathrm{H}^{+}\left(\mathrm{H}_{2} \mathrm{O}\right)$ ion. This result is similar to that observed for $\mathrm{H}_{3}{ }^{+}$fragment produced in the dissociation after excitation induced by collision of $\mathrm{H}^{+}\left(\mathrm{H}_{2}\right)_{11}$ shown in Fig $1 \mathrm{~b}$.

The structure of protonated water clusters has been extensively studied and it is admitted that they are built from two possible protonated cores: the Eigen and the Zundel structures ${ }^{34}$. The Eigen type consists of a proton strongly bound to a single water forming $\mathrm{H}_{3} \mathrm{O}^{+}$, the hydronium ion, while in the Zundel type the proton is shared between two water units forming $\mathrm{H}_{2} \mathrm{O} \cdots \mathrm{H}^{+\cdots} \mathrm{OH}_{2}$. These limiting structures are called the Eigen and Zundel models for the proton in water ${ }^{34}$. For protonated clusters with a small number of molecules (2-7 molecules) various structures have been optimized by ab-initio calculations and for all the cluster sizes Eigen and Zundel type structures are found to be very closed to each other from an energetic point of view ${ }^{35}$ 
The cross-section for the production of the $\mathrm{H}_{3} \mathrm{O}^{+}$ion from collision induced dissociation of protonated water cluster have been measured versus the number of molecules in the cluster.

$$
\mathrm{H}^{+}\left(\mathrm{H}_{2} \mathrm{O}\right)_{\mathrm{m}}+\mathrm{Ar} \rightarrow \mathrm{H}_{3} \mathrm{O}^{+}+(\mathrm{m}-1)\left(\mathrm{H}_{2} \mathrm{O}\right)
$$

The $\mathrm{H}_{3} \mathrm{O}^{+}$production cross sections in CID of $8 \mathrm{keV}-\mathrm{H}^{+}\left(\mathrm{H}_{2} \mathrm{O}\right)_{\mathrm{m}=2-7}$ on an argon gas target are plotted in Figure 4. From $m=2$ up to 5 the cross section is nearly constant and then increases for $n=6$ and 7. As discussed in the case of hydrogen clusters, the increase of the cross section for the complete dissociation process with the cluster size cannot be understood via a collisional excitation of a positively charged core followed by the loss of all the molecules.

\section{Conclusion}

By the selective observation of the processes in a multiparametric event by event detection technique, the results have shown how different excitation mechanisms compete and various relaxation phenomena occur in collision induced dissociation experiment. The relaxation of molecular cluster after excitation induced by collision is observed in the case of the two investigated cluster cations. In both cases, the unimolecular evaporation process is observed. But a high proportion of complete dissociation of the cluster appears. Such behavior was observed in collision induced dissociation of protonated water clusters and associated with a multifragmentation process ${ }^{36}$. Differently in the case of collision induced dissociation of mixed cluster anions, the cluster dissociation in all its constituents has been interpreted in the framework of statistical unimolecular evaporation model ${ }^{37}$. In contrast the present results could also suggest that the observed effect is related to the charge localisation in the cluster cations. According to ab initio calculations on protonated hydrogen clusters, the localisation of the positive charge becomes less restricted with increasing cluster size and/or temperature ${ }^{38,39}$. Thus, the loss of molecules requires a relaxation of the core which could 
induce the complete dissociation of the cluster. Concerning the protonated water clusters, the charge localisation is strongly different for the Eigen and the Zundel type structures. Therefore for the latter the relaxation of the molecular system after excitation by collision could favor the dissociation channel producing the $\mathrm{H}_{3} \mathrm{O}^{+}$ion, rather than the stabilization of the Zundel structure. Thus, the increase of the production of the $\mathrm{H}_{3} \mathrm{O}^{+}$cation cross-section observed here for protonated water clusters with size of 6 and 7 could be associated with the contribution of Zundel type structure in the protonated cluster beam for the $\mathrm{H}^{+}\left(\mathrm{H}_{2} \mathrm{O}\right)_{6}$ and $\mathrm{H}^{+}\left(\mathrm{H}_{2} \mathrm{O}\right)_{7}$ clusters ions. Signature for the occurrence of Zundel type structures for protonated cluster ions with six and seven molecules has already been observed in infrared spectroscopy ${ }^{40}$. 


\section{FIGURES}

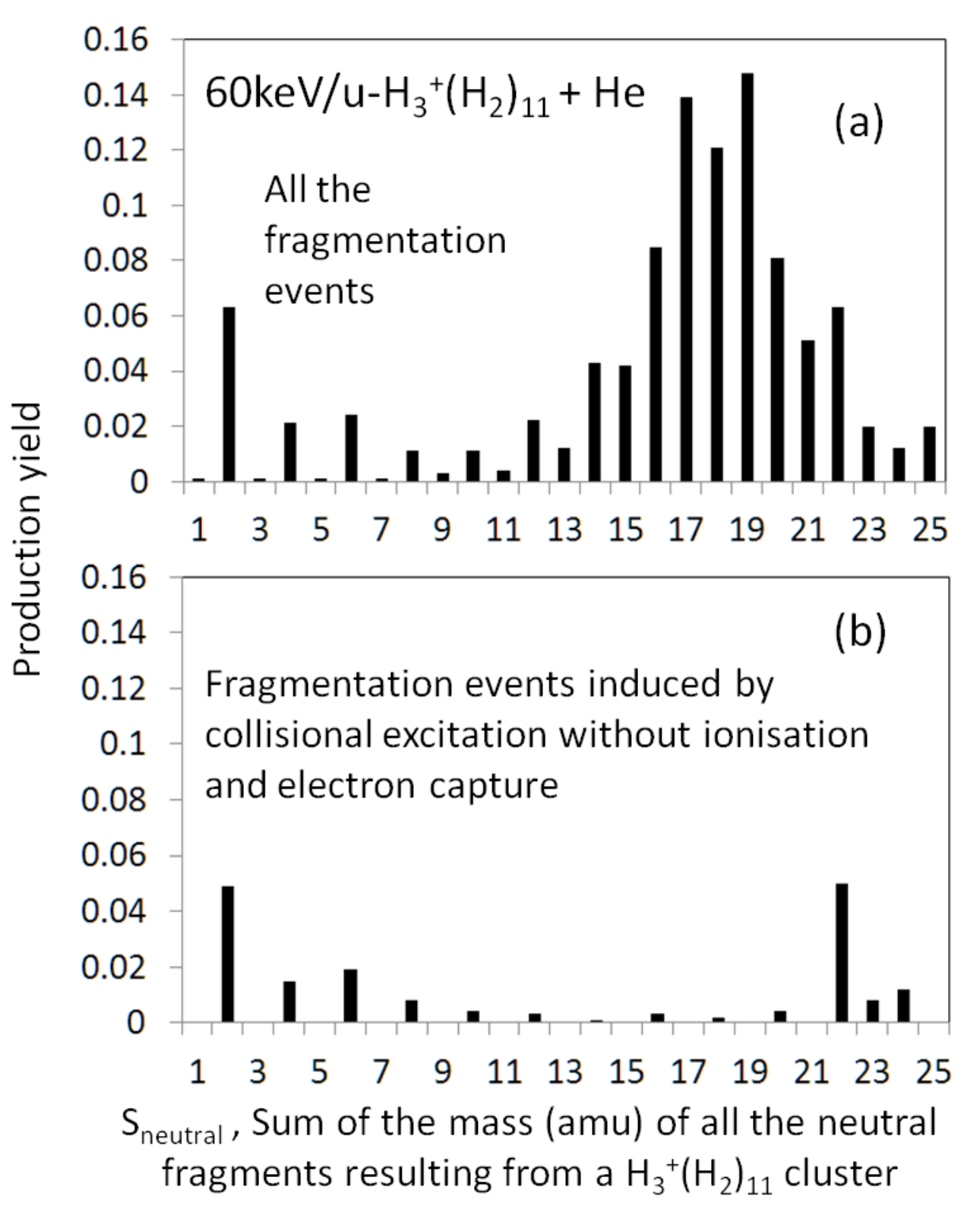

Figure 1: The variety in the fragmentation channels is shown via the histogram built with $10^{4}$ fragmentation events sorted with respect to the value of the sum of the mass (amu) of all the neutral fragments resulting from the $\mathrm{H}_{3}{ }^{+}\left(\mathrm{H}_{2}\right)_{11}$ cluster fragmentation.

(a) all the fragmentation events.

(b) fragmentation events induced by collisional excitation without ionization and electroncapture. 


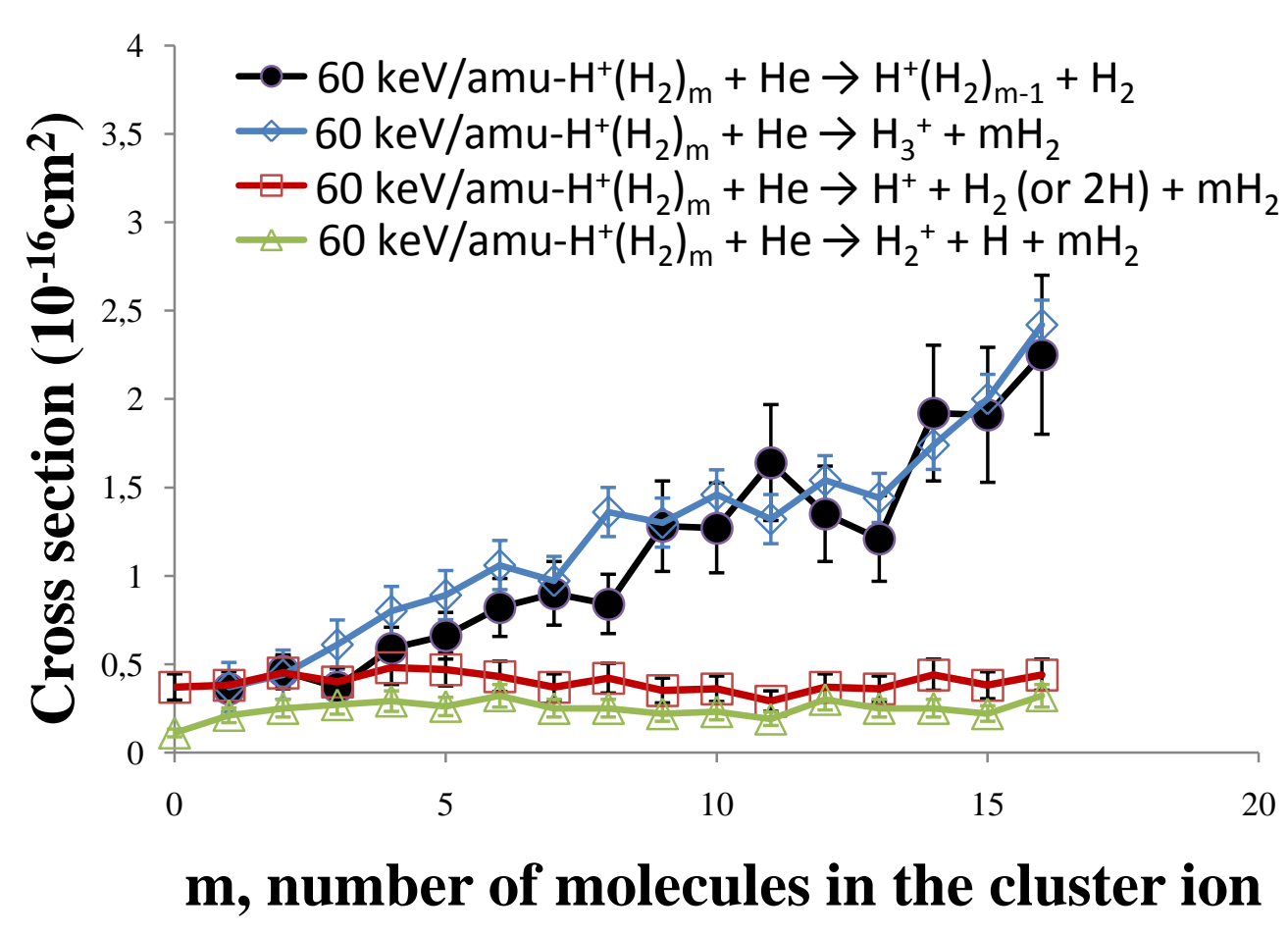

Figure 2: Cross section of the $\mathrm{H}_{3}{ }^{+}$fragment production without collision induced ionisation versus $\mathrm{m}$, the number of molecules in the cluster. 


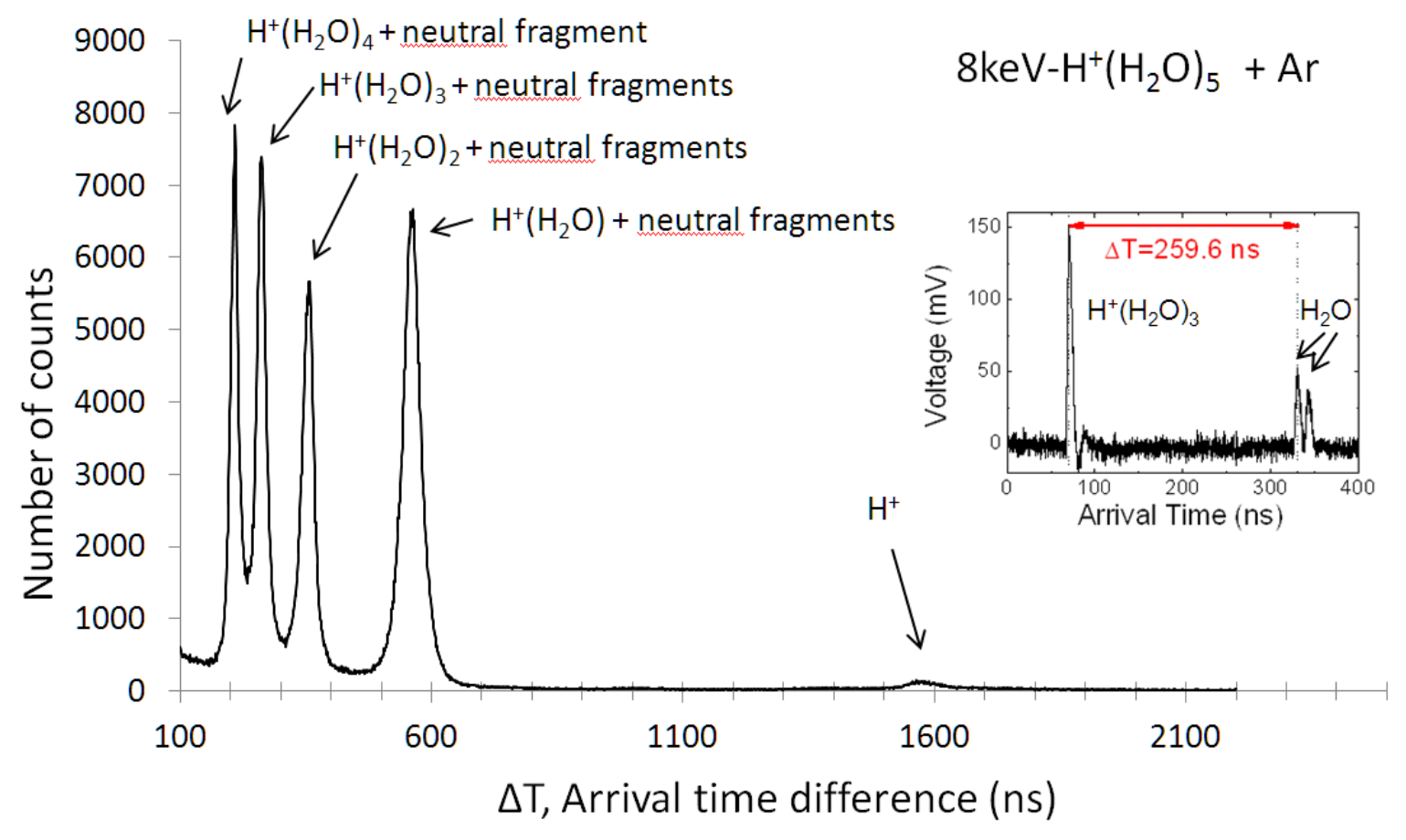

Figure 3: Collision induced dissociation of $8 \mathrm{keV}-\mathrm{H}^{+}\left(\mathrm{H}_{2} \mathrm{O}\right)_{5}$ on an argon atom: fragmentation channels observed via the COINTOF mass spectrometry technique. Insert: typical example of the signal recorded for the dissociation of a single cluster ion in the channel $\mathrm{H}^{+}\left(\mathrm{H}_{2} \mathrm{O}\right)_{5}+\mathrm{Ar} \rightarrow$ $\mathrm{H}^{+}\left(\mathrm{H}_{2} \mathrm{O}\right)_{3}+2 \mathrm{H}_{2} \mathrm{O}$ 


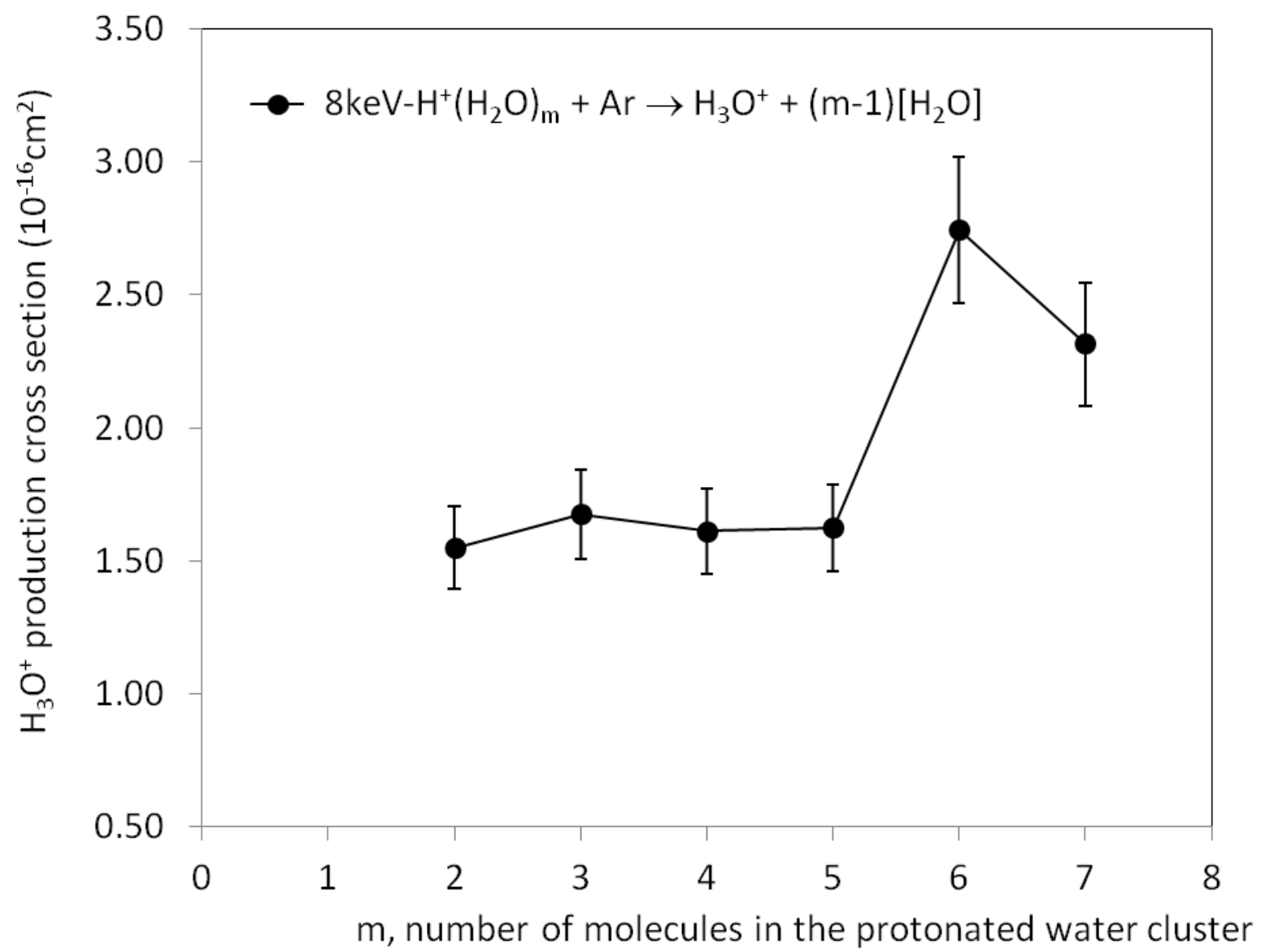

Figure 4: $\mathrm{H}_{3} \mathrm{O}^{+}$fragment production cross section corresponding to the selected fragmentation channel $\mathrm{H}^{+}\left(\mathrm{H}_{2} \mathrm{O}\right)_{\mathrm{m}}+\mathrm{Ar} \rightarrow \mathrm{H}_{3} \mathrm{O}^{+}+(\mathrm{m}-1)\left[\mathrm{H}_{2} \mathrm{O}\right]$ versus $\mathrm{m}$, the number of $\mathrm{H}_{2} \mathrm{O}$ molecules in the protonated water cluster. 


\section{REFERENCES}

${ }^{1}$ T. Schlathölter, in Radiation damage in biomolecular system, Biological and Medical Physics, Biomedical Engineering, G. García, M. Fuss (Editors) Springer 2012

${ }^{2}$ T. Oka, Rev. Mod. Phys. 64, 1141-1149 (1992)

${ }^{3}$ B. Coupier, B. Farizon, M. Farizon, M.J. Gaillard, F. Gobet, N.V. De Castro Faria, G. Jalbert, S. Ouaskit, M. Carre, B. Gstir, G. Hanel, S. Denifl, L. Feketeova, P. Scheier, T.D. Märk, European Physical Journal D 20 (2002) 459-468

${ }^{4}$ J. de Vries, R. Hoekstra, R. Morgenstern, and T. Schlathölter, Phys. Rev. Lett. , 91, 053401 (2003)

${ }^{5}$ G.Hanel, B. Gstir, S. Denifl, P. Scheier,B. Farizon, M. Farizon, E. Illenberger, and T.D. Märk Phys. Rev. Lett. , 90, 188104 (2003)

${ }^{6}$ F. Gobet, B. Farizon, M. Farizon, M.J. Gaillard, S. Louc, N. Goncalves, M. Barbatti, H. Luna, G. Jalbert, N.V. de Castro Faria, M.C. Bacchus Montabonel, J.P. Buchet, M. Carré, T.D. Märk, Phys. Rev. Lett. 86, 4263-4266 (2001)

${ }^{7}$ C. Teyssier, R. Fillol, H. Abdoul-Carime, B. Farizon, M. Farizon and T.D. Märk, A novel "COrrelated Ion and Neutral Time Of Flight" Method: event-by-event detection of neutral and charged fragments in Collision Induced Dissociation (CID) of mass selected ions”, Rev. Sci. Instrum. (accepted)

${ }^{8}$ M.Ohkubo et al, Int.J.Mass Spectrom. 299, 94 (2011)

${ }^{9}$ I. Stich, D. Marx, M. Parinello, K. Terakura, J.Chem.Phys. 107 (1997)9482

${ }^{10}$ I. Stich, D. Marx, M. Parinello, K. Terakura, J.Chem.Phys. 78 (1997)3699

${ }^{11}$ M. Farizon, H. Chermette, B. Farizon-Mazuy, J. Chem. Phys. 96 (1992) 1325 and references therein.

${ }^{12}$ B. Farizon, M. Farizon, M.J. Gaillard, E. Gerlic, S. Ouaskit, Nucl. Instr. And Meth. B 88 (1994).

${ }^{13}$ B. Farizon et al., Int. J. Mass Spectrom. Ion Process. 144 (1995) 79

${ }^{14}$ C Sheehan, W J Lennard and J B A Mitchell, Meas. Sci. Technol. 11 (2000) L5

${ }^{15}$ B. Farizon et al., Phys. Rev. Lett. 81 (1998) 4108.

${ }^{16}$ B. Farizon et al., Eur. Phys. J. D 5 (1999)5.

${ }^{17}$ F. Gobet et al. Int. J. Mass Spectrom. 2020 (2002) 263

${ }^{18}$ F. Gobet, Thèse de doctorat, Université Lyon 1, 2001.

${ }^{19}$ B. Farizon et al., Nucl. Instr. And Meth. B 101 (1995) 287.

${ }^{20}$ B. Farizon et al., Int. J. Mass Spectrom. Ion Process. 164 (1997) 225

${ }^{21}$ B. Farizon et al., Chemical Physics Letters 252 (1996) 147-152

22 C.E. Klots, J. Phys. Chem. 92, 5864 (1988).

${ }^{23}$ S. Louc, M. Farizon, B. Farizon, M.J. Gaillard, N.Gonçalves, H.Luna, G.Jalbert, N.V. de Castro Faria, M. Carré, J.P. Buchet, M.C. Bacchus, Phys.Rev.A 58 (1998) 3802.

${ }^{24}$ L. Sanche, Nature, 461, 358 (2009). 
${ }^{25}$ S. Bari, P. Sobocinski, J. Postma, F. Alvarado, R. Hoekstra, V. Bernigaud, B. Manil, J. Rangama, B. Huber, and T. Schlathölter, J. Chem. Phys., 128, 074306 (2008).

${ }^{26}$ J. Tabet, S. Eden, S. Feil, H. Abdoul-Carime, B. Farizon, M. Farizon, S. Ouaskit, and T.D. Märk, Phys. Rev. A, 81, 012711 (2010); Phys. Rev. A, 82, 022703 (2010).

${ }^{27}$ G.V. Buxton and C.L Greenstock, W.Ph. Helman, A.B. Ross, JPCRD, 17:2, 513-886 (1988).

${ }^{28}$ M.S. Kreipl, W. Friedland and H.G. Paretzke, Radiation and Environmental Biophysics, 48, 11 (2009).

${ }^{29}$ P. Auffinger and E. Westhof, J. Mol. Biol.,300, 1113 (2000).

${ }^{30}$ G. Bruny, S. Eden, S. Feil, R. Fillol, K. El Farkh, M. M. Harb, C. Teyssier, S. Ouaskit, H. Abdoul-

Carime, B. Farizon, M. Farizon, and T. D. Märk, Rev. Sci. Instrum., 83, 013305 (2012)

${ }^{31}$ H. Abdoul-Carime, F. Berthias, B. Farizon, M. Farizon, to be published.

${ }^{32}$ T. Mark and A. Castleman, «Experimental Studies on Cluster Ions », Adv. At. Mol. Phys., vol. 20, p. 65-172, 1985.

${ }^{33}$ F. Berthias, V. Buridon, H. Abdoul-Carime, B. Farizon, M. Farizon, P.M. Dinh, P.-G. Reinhard, E. Suraud, T.D. Märk, Collision-induced dissociation cross section of protonated water clusters, to be published

${ }^{34}$ D.Marx, et al., Nature 397 (1999) 601

${ }^{35}$ J. C. Jiang, Y. S. Wang, H. C. Chang, S. H. Lin, Y. T. Lee, G. Niedner-Schatteburg, and H. C. Chang, J. Am. Chem. Soc., 122 (2000) 1398.

${ }^{36}$ S. Tomita, J. S. Forster, P. Hvelplund, A. S. Jensen, and S. B. Nielsen, Eur. Phys. J. D, 16 (2001)119.

${ }^{37}$ B. Liu, S. Brøndsted Nielsen, and P. Hvelplund, H. Zettergren and H. Cederquist, B. Manil and B.

A. Huber, Phys. Rev. Letters 97, 133401 (2006).

${ }^{38}$ Y. Ohta, K. Ohta, K. Kinugawa, Journal of Chemical Physics, 121 (2004) 10991.

${ }^{39}$ H. Chermette and I. V. Ymmud, Phys. Rev. B 63, 165427 (2001).

${ }^{40}$ J. M. Headrick, E. G. Diken, R. S. Walters, N. I. Hammer, R. A. Christie, J. Cui, E. M. Myshakin, M. A. Duncan, M. A. Johnson, et K. D. Jordan, Science 308 (2005)1765. 